\title{
Redes, alianças estratégicas e intercooperação: o caso da cadeia produtiva de carne bovina
}

\author{
Marcelo José Braga ${ }^{1}$
}

${ }^{1}$ Departamento de Economia Rural da UFV.

RESUMO - O objetivo neste trabalho é discutir a formação de parcerias, redes e alianças estratégicas na cadeia de produção de carne bovina brasileira. É apresentada discussão acerca dos conceitos básicos de rede, alianças estratégicas e intercooperação. São analisados quatro casos, baseados na literatura existente. Finalmente, conclui-se apontando as razões de sucesso em uma aliança na cadeia analisada.

Palvras-chave: aliança estratégica, produção de carne bovina, redes

\section{Networks, strategic alliances and cooperation: the case of production chain of beef meat}

\begin{abstract}
The objective of this paper is to discuss the formation of partnerships, networks and strategic alliances in the production chain of Brazilian beef. The basic concepts of networks, strategic alliances and, cooperation are discussed. Four cases of alliances are analyzed, based on the existent literature. Finally, the work is finished pointing the success reasons in an alliance.
\end{abstract}

Key Words: beef production, networks, strategic alliance

\section{Introdução}

A década de 1990 foi marcada por crescente internacionalização das economias nacionais. A expansão do fluxo de mercadorias e investimentos entre os países causou grandes mudanças em praticamente todos os países do mundo, acirrando a concorrência internacional. No Brasil não foi diferente, e praticamente todos os setores da economia foram fortemente afetados pela globalização e tiveram a necessidade de se adequar a essa nova realidade. A competitividade empresarial, aliada às necessidades de adaptação ao mercado, tem-se caracterizado como uma das maiores exigências para as organizações, principalmente aquelas voltadas ao agronegócio, devido ao maior risco e à menor previsibilidade inerente às atividades agropecuárias .

Nesse cenário, alguns setores e empresas não conseguiram obter desempenho suficiente. Outros, porém, se modernizaram e conseguiram atender os desafios competitivos. Isso ocorre devido, sobretudo, a atitudes estratégicas dos agentes.

A esse conjunto de atitudes denomina-se estratégia competitiva, e "sua meta para uma unidade empresarial é encontrar uma posição em que a organização possa melhor se defender contra as forças que atuam sobre ela, ou influenciá-las em seu favor" (Porter, 1986).

Esse conceito se fundamenta na idéia de que o setor desenvolve suas estratégias de modo a se ajustar ao meio ambiente. Ou seja, são as crescentes mudanças no ambiente de negócios que têm levado as organizações a alterarem constantemente suas estratégias competitivas (Rosseto, 2000).

Segundo Porter (1986), “a melhor estratégia para uma dada empresa é, em última análise, uma solução única que reflete suas circunstâncias particulares”. O autor afirma que, em sentido mais amplo, podem-se encontrar três estratégias genéricas internamente consistentes, as quais podem ser usadas isoladamente ou de forma combinada, sendo: liderança no custo total, diferenciação e enfoque.

Pode-se mencionar a existência de diversas outras estratégias que norteiam o ajustamento competitivo, sendo agrupadas nos seguintes blocos: fusão, integração vertical, alianças estratégicas (acordo ou parceria, "holding” e “joint venture”) e diversificação (de negócios, de produtos e de mercados).

As redes de empresa são definidas como grupo de organizações com interesses comuns, que se unem para a

Corresponding author: mjbraga@ufv.br 
melhoria da competitividade de determinado setor ou segmento e cooperam entre si. Este conceito é aplicado a diferentes formas de relações entre firmas, como por exemplo, joint ventures, alianças estratégicas, relações de terceirização e subcontratação, distritos industriais, consórcios, redes sociais, redes de cooperação entre pequenas e médias empresas.

Conforme Ward (2002), as alianças estratégicas e os diferentes arranjos verticais tem sido um assunto controverso na cadeia de carne bovina, com aspectos positivos e negativos. Porém, o autor observou um crescimento e desenvolvimento desses mecanismos. Chaddad \& Mulrony (2005) identificaram 67 alianças estratégicas na pecuária de corte bovino americana.

Nesse sentido, o objetivo no presente artigo é discutir a formação de parcerias, redes e alianças estratégicas na cadeia de produção de carne bovina brasileira. Para tal, o artigo está organizado em três partes, além desta introdução. A próxima seção apresenta os conceitos básicos. A seguir, discutem-se quatro casos, baseados na literatura existente. Finalmente, conclui-se o trabalho apontando as razões de sucesso em uma aliança na cadeia analisada.

\section{Definições básicas}

As redes de empresa são definidas como grupo de organizações com interesses comuns, que se unem para a melhoria da competitividade de um determinado setor ou segmento e cooperam entre si. Este conceito é aplicado a diferentes formas de relações entre firmas, como por exemplo, joint ventures, alianças estratégicas, relações de terceirização e subcontratação, distritos industriais, consórcios, redes sociais, redes de cooperação entre pequenas e médias empresas.

Para Fensterseifer (2000) uma rede de empresas pode ser definida como um complexo de relações cooperativas interorganizacionais que dinamizam a ação de seus agentes em torno de objetivos comuns ou complementares. A rede está ligada a quatro objetivos estratégicos: (1) vantagens baseadas na busca de complementariedade, como, por exemplo, aumentar a penetração em novos mercados ou ampliação dos mercados atuais, (2) criação de poder de compra, por exemplo, em acordos de redução de custos de suprimentos ou de aumento de poder de mercado, em função do peso econômico, da imagem e da reputação; (3) ampliação de base técnica, como atividades de pesquisa e Desenvolvimento; (4) ampliação dos conhecimentos: redes de cooperação podem, através de aprendizagem coletiva, gerar os conhecimentos e as informações necessárias a cada membro (Jeronimo, 2005).
A coordenação vertical envolve o emprego de um amplo conjunto de procedimentos buscando harmonizar ou sincronizar as atividades ao longo da cadeia produtiva, principalmente entre a produção pecuária e a demanda final, em nível de varejo. A coordenação vertical pode ocorrer por meio do sistema de preços de mercado, via cooperação entre os agentes (contratos, parcerias, alianças) e via a integração vertical (Ward, 2002).

A cooperação vertical é definida como uma relação entre empresas ou organizações em dois ou mais estágios da cadeia produtiva, sem a propriedade completa ou o controle por parte de um das empresas individuais. Os participantes da cooperação vertical mantêm sua independência, porém compartilham informações para estabelecer preços e melhorar o fluxo de produtos e informação entre os estágios do da cadeia.

O termo aliança estratégica é mais amplo e abrange vários tipos de acordos verticais. Para Yoshino \& Rangan (1996), em uma aliança estratégica as participantes permanecem independentes depois da formação da aliança; compartilham dos benefícios da aliança e controlam o desempenho das tarefas especificadas; e contribuem continuamente em uma ou mais áreas estratégicas fundamentais.

A maior interdependência das atividades das cadeias produtivas no sistema alimentar estimula a formação de alianças entre empresas. Segundo Jank \& Nassar (1995), as alianças estratégicas são caracterizadas por envolverem empresas no atingimento de um objetivo estratégico comum, a fim de melhorar a sua posição competitiva no mercado.

No caso da carne bovina, a pesquisa realizada pelo IEL, CNA e SEBRAE (2000) separou as vantagens das alianças estratégicas de acordo com os produtores, frigoríficos e distribuidores. O pecuarista seria beneficiado por meio do aumento da rentabilidade; da absorção e utilização de técnicas de manejo mais modernas, que podem propiciar ganhos de produtividade no médio e no longo prazo; da garantia de venda dos animais, para frigoríficos que valorizem o produto dentro de certas especificações; dos ganhos em termos de diferenciação do produto a longo prazo. Já no caso dos frigoríficos os benefícios seriam garantia de regularidade de abastecimento; garantia de venda do produto; e diferenciação do frigorífico. O segmento de distribuição seria beneficiado com a garantia de regularidade de abastecimento e a disponibilização de produto com garantia de origem e qualidade ao consumidor final.

Pode-se destacar que a principal vantagem das alianças estratégicas é a agregação de valor ao produto. Na medida em que os participantes de uma aliança compartilham 
informações entre si, podem responder de forma mais adequada e rápida à demanda dos consumidores. Isso pode ocorrer, conforme Ferreira \& Barcellos (2006), por meio de melhorias de qualidade, redução de tempo de chegada do produto ao mercado, melhoria na distribuição de produtos e matérias primas.

\section{A Intercooperação ou Cooperação entre} Cooperativas potencializa a nível macro a cooperação intra-organizacional inerente às cooperativas. Segundo a Aliança Cooperativa Internacional ACI (2003) ${ }^{1}$, “as cooperativas servem de forma mais eficaz os seus membros e dão mais força ao movimento cooperativo, trabalhando em conjunto, através das estruturas locais, regionais, nacionais e internacionais".

A Intercooperação pode acontecer simplesmente através de trocas de informações e experiências, ou ainda através da compra e/ou vendas em comum. Outro aspecto importante do princípio é a possibilidade de mobilização das cooperativas na defesa de seus interesses.

Casos de formação de alianças estratégicas

Saab et al. (2009), Macedo (2009) e Macedo \& Moraes (2009) analisaram quatro casos de alianças estratégicas na carne bovina brasileira, que serão discutidos a seguir.

\section{Aliança mercadológica de Guarapuava}

A Aliança mercadológica de Guarapuava é composta e liderada por produtores de novilhos precoces no município de Guarapuava (Paraná), que desenvolvem acordos de comercialização com frigoríficos e redes de varejo no Estado do Paraná.

A aliança de Guarapuava, caracterizada por uma rede de relacionamentos horizontal, foi formada pela organização de 18 produtores, que coordena as transações do produtor ao varejo de carnes provenientes de animais superprecoces. Neste arranjo institucional, não há a emergência de um agente com poder indutor sobre os demais participantes, o que gera dependência mútua.

Na classificação apresentada por Grandori \& Soda (1995), o tipo de rede que mais se assemelha ao caso analisado é a rede social simétrica. Ela está baseada em paridade, reciprocidade e fortes laços pessoais; há troca de informações entre os agentes, utilizam-se mecanismos de tomada de decisão em conjunto, há compartilhamento de normas e valores culturais, além da utilização do princípio de intercooperação e de mecanismos de controle social entre o grupo, como a reputação e sanções do grupo ao comportamento oportunista.

O mecanismo de coesão necessita de incentivos que reduzam o oportunismo entre os agentes. Para tal, podem ser empregados mecanismos formais e informais. Os mecanismos formais baseiam-se nos contratos de fornecimento e nas condições de exclusividade entre os participantes. Os mecanismos informais são exercidos mediante a constituição do controle social contra ações oportunistas. Neste caso, é fundamental o desenvolvimento das relações de confiança.

A confiança é entendida como a segurança mútua de que nenhum agente irá explorar as vulnerabilidades dos demais. Segundo Barney \& Hansen (1994), há três distintos tipos de confiança (Tabela 1).

A confiança desponta para as organizações como elemento determinante do grau de adesão e comprometimento com os esforços empreendidos pelos pares. Em se tratando das alianças cooperativas, a confiança assume papel ainda mais importante, devido às características inerentes ao modelo cooperativo, conforme destacam Bertolin et al. (2008).

Deve-se observar que o aumento de confiança entre os agentes pode ser acompanhado de redução dos mecanismos formais, ou seja, menores serão as salvaguardas necessárias em estruturas de governança.

Perrow (1992) elenca as condições facilitadoras das relações de confiança: existir pouca diferença entre tamanho, poder ou posição estratégica das firmas; haver periódica rotação de lideranças; estabelecer relações a longo prazo; existir semelhanças entre processos e técnicas das firmas; existir compartilhamento de informações sobre mercados, tecnologias, lucratividade; haver similaridades de recompensa financeira para os participantes; existir vantagem econômica devido a experiência coletiva.

Conforme Agrorede (2208), no final de 2007, os pecuaristas constituíram a Cooperaliança - Cooperativa Agroindustrial Aliança de Carnes Nobres Vale do Jordão. Por meio da cooperativa, “os produtores passarão a elaborar cortes especiais, usar marca própria e buscar até espaço no mercado internacional”.

A escala, associada à diferenciação, permite à aos produtores consolidarem uma marca forte lastreada em um portfólio diferenciado de produtos, ligado a esforços de pesquisas e desenvolvimento. A diferenciação,

\footnotetext{
${ }^{1}$ Os princípios cooperativistas em vigor foram revalidados pela assembléia da Aliança Cooperativista Internacional (ACI) em 1995, sendo eles: Adesão voluntária e livre; Gestão democrática pelos membros; Participação econômica dos membros; Autonomia e independência; Educação, formação e informação; Intercooperação; e Interesse pela comunidade. Para mais detalhes, consultar ACI (2003).
} 
Tabela 1 - Tipos de confiança

\begin{tabular}{|c|c|}
\hline Tipos de confiança & Características de cada um dos tipos de confiança \\
\hline Forma "Fraca" de confiança & $\begin{array}{l}\text { A forma fraca da confiança é possível porque não existem vulnerabilidades; } \\
\text { emerge porque existem oportunidades limitadas ao oportunismo. } \\
\text { É encontrada nos mercados competitivos, como no mercado de commodity (leite, soja), } \\
\text { e sempre que a qualidade dos bens ou serviços transacionados pode ser avaliada a baixo custo. }\end{array}$ \\
\hline Forma “Semi - Forte” de Confiança & $\begin{array}{l}\text { Essa forma de confiança é possível, apesar das vulnerabilidades na transação, } \\
\text { porque usam mecanismos de governança que impõem custos ao comportamento oportunista. } \\
\text { Mecanismos de governança sociais (menor custo) podem ser utilizados no lugar de mecanismos } \\
\text { econômicos (maior custo): firmas que obtém a forma semi-forte de confiança através de formas } \\
\text { intermediárias de governança podem ter uma vantagem competitiva (menor custo) sobre as firmas } \\
\text { com forma hierárquica de governança. Por exemplo, a GM e a Toyota que usam governança social } \\
\text { para gerar formas semi-fortes de confiança têm vantagem competitiva de custos sobre concorrentes. }\end{array}$ \\
\hline Forma "Forte" de confiança & $\begin{array}{l}\text { Há vulnerabilidades que não são exploradas pelos parceiros existindo (ou não) mecanismos de } \\
\text { governança social ou econômica, porque a confiança emerge dos princípios individuais (confiança } \\
\text { de princípio) e o comportamento oportunista violaria os valores, princípios e padrões de } \\
\text { comportamentos. Nas firmas é associada à cultura organizacional e a indivíduos (ou grupos). A forma } \\
\text { forte depende de que todos se comportem de modo confiável, senão é necessário criar mecanismos } \\
\text { de confiança. Agentes envolvidos num contexto de alta confiabilidade terão vantagem } \\
\text { de custos sobre aqueles em meio a um contexto de confiabilidade intermediária. }\end{array}$ \\
\hline
\end{tabular}

Fonte: Jeronimo (2005).

acompanhada do processamento em escala, permite também o acesso a vários mercados, não se restringindo à comercialização regional. Nesses mercados, o volume constitui fator essencial na competitividade, uma vez que permite a elevação do poder de negociação com as grande

\section{Programa de carne de qualidade Pão de Açúcar}

Conforme Saab et al. (2009), este programa, iniciado em 2005, tem como objetivo garantir o padrão de qualidade da carne vendida nesta rede de supermercados. Este programa realiza um conjunto de exigências sobre o sistema de produção “os animais sejam produzidos a partir do cruzamento de matrizes da raça Nelore com sêmen da raça continental Rubia Galega, devem ser terminados em semiconfinamento e serem, abatidos com a idade entre 12 e 20 meses e peso vivo entre 420 e 490 kg” (Saab et al., 2009).

Conforme estes autores, a coordenação ocorre por meio de relação contratual direta entre a rede a rede varejista e os produtores. No caso, o abate de animais é feito pelo frigorífico Marfrig.

O segmento que mais se destaca no setor varejista é o supermercadista, que, a exemplo de todo o setor, vem passando por intensas transformações, tais como reestruturações e fusões. A internacionalização da economia brasileira favoreceu o estabelecimento, no país, de redes de supermercados internacionais, dentre as quais se destacaram a portuguesa Sonae, a norte-americana WalMart o grupo Holandês ROYAL HOLD e o GRUPO
CASSINO da França, entre outros. A estratégia desses grandes grupos estrangeiros concentrou-se principalmente na aquisição de supermercados nacionais e posterior expansão das operações com a abertura de novas lojas, o que gerou pressões competitivas sobre todos os participantes do mercado. Essas estratégias contribuíram ainda para elevar os níveis de concentração no setor, que aumentam o poder de barganha destes.

Neste caso, tem-se o exemplo de uma rede verticalizada, que pode apresentar os problemas de concentração de poder e de informação em níveis hierárquicos superiores; de dificuldades de troca de informações, que circula em fluxos definidos de cima par abaixo como ordens e de baixo para cima como retorno ou avaliação do entendimento e cumprimento das ordens; e delegação de poder.

Segundo Macedo et al. (2009), os incentivos aos participantes são oriundos de ganhos econômicos proporcionados pela coordenação do líder. A liderança do varejo atua mediante a coordenação vertical a partir de seus objetivos estratégicos, vinculados à prioridade de fornecimento de produtos diferenciados aos seus clientes, que estabelecem o conjunto de incentivos e obrigações aos demais participantes.

\section{Programa Carne Angus Certificada ${ }^{2}$}

Esta é uma aliança entre a Associação Brasileira do Angus (ABA), a indústria frigorífica (Mercosul (RS) e Marfrig (SP) e as redes de supermercados Pão de Açúcar e

\footnotetext{
${ }^{2}$ No endereço eletrônico <http: www.carneangus.org.br> estão disponibilizadas informações sobre a aliança.
} 
Zaffari, no Rio Grande do Sul. De acordo com Macedo (2009), os benefícios para a ABA são a expansão da raça Angus no território nacional, e para os frigoríficos a comercialização de carnes de maior valor agregado. Nesta aliança, há compartilhamento de liderança entre a associação e os frigoríficos, com incentivos horizontais, mediante a constituição do grupo de produtores da raça Angus, e de incentivos verticais, pelos mecanismos de premiação e de classificação de carcaças.

A ABA disponibiliza veterinários contratados e treinados para fiscalizar os animais abatidos e certificar a carne. Participam ainda do Programa a rede de supermercados Zaffari, o restaurante Barranco, de Porto Alegre (RS), e a butique de carnes VPJ Beef (Saab et al., 2009).

A participação dos produtores é induzida tão somente pela premiação dos atributos da padronização das carcaças abatidas. Não são firmados contratos a termo ou a exigência de exclusividade na comercialização dos animais, dessa forma, a densidade das relações entre os participantes não se aprofunda e as transações são mantidas sob a o mercado spot (Macedo \& Moraes, 2009).

\section{Montana Premium Beef}

Montana Premium Beef é parceria entre produtores da raça Montana, que exercem a liderança, e o Frigorífico Marfrig com o objetivo de produção de cortes de qualidade superior. O projeto foi criado com o intuito de congregar um grupo seleto de produtores da raça Montana para a verticalização da produção desde a cria, recria e engorda dos animais, passando pela parceria com o Frigorífico Marfrig, até o varejo, com a formação de uma rede de churrascarias e de fast food, operadas mediante franquias, com fornecimento próprio das carnes comercializadas. Além disso, constituiu-se a marca Montana Premium Beef para a comercialização de cortes especiais embalados através das redes Pão de Açúcar e Zaffari (Macedo, 2009)

Conforme o Fundo de Desenvolvimento da Pecuária (FUNDEPEC), o primeiro passo foi o desenvolvimento do padrão do produto a ser comercializado. Devido a não organização dos produtores, não são empregados instrumentos de coordenação horizontais e prevalecem os instrumentos de premiação de mercado dos padrões requeridos pela tabela de classificação. A baixa coordenação entre os pecuaristas, em virtude de não se constituir um grupo organizado de fornecedores, reduz a capacidade da aliança alongar suas escalas de abate e elevar a homogeneidade dos lotes de animais comercializados. (Macedo \& Moraes, 2009).

Em todos esses casos, a consolidação está conjugada às benesses advindas das economias de escala e de escopo, do aproveitamento de vantagens complementares e do fortalecimento da marca e do poder de mercado, variáveis determinantes na dinâmica competitiva do mercado.

\section{Conclusões}

Ward (2002) identifica quatro fatores importantes para o sucesso das alianças verticais.

O primeiro refere-se à existência de objetivos comuns. Estes devem ser mutuamente benéficos para os participantes. A formulação específica e clara de objetivos pode permitir aos participantes a forma mais precisa combinar seus objetivos com os objetivos da aliança. Também, o foco no longo prazo sinaliza para a estabilidade do ambiente, induzindo os membros a buscarem os ajustes necessários ao longo do tempo.

O segundo está relacionado ao fluxo de informações. Quanto maior o compartilhamento de informações, menor atrito e maior a coesão social entre os membros. A assimetria de informação descreve o fenômeno segundo o qual alguns agentes econômicos têm mais informação do que sua contrapartida, moldando um cenário incerto e inseguro. Nessa concepção, o grau de incerteza pode assumir a forma contingencial (ações aleatórias da natureza e do mercado consumidor), e de assimetria de informação, desconhecimento por um tomador de decisão das informações possuídas pelos outros agentes envolvidos na transação.

O terceiro refere-se à geração de comprometimento dos membros no longo prazo, por meio de requerimentos de capital. Se, por exemplo, os produtores estão dispostos a tornarem-se certificados ou licenciados, eles provavelmente terão um maior incentivo para garantir a aliança seja bem sucedida.

Finalmente, a especificação racial garante maior homogeneidade do sistema de produção, facilitando a aplicação de mecanismos de controle no grupo.

\section{Referências}

AGROREDE NOTÍCIAS. Pecuaristas de Guarapuava criam Cooperativa. Curitiba, $\mathrm{N}^{\circ} 2$, Ano 1 2008. p.6.

BARCELLOS, M.D.; FERREIRA, G.C. Vantagens e desvantagens das alianças estratégicas: uma análise sob a ótica dos agentes da cadeia produtiva da carne bovina. Organizações Rurais \& Agroindustriais, v.8, n.1, p.117-130, 2006.

BERTOLIN, R.V.; SANTOS, A.C.; LIMA, J.B. et al. Assimetria de informação e confiança em interações cooperativas. Revista Administração Contemporânea, v.12, n.1, p.5981, 2008.

CHADDAD, F.R.; MULRONY, B.R. Strategic alliances in the U.S beef suply chain. Journal of Food Distribution Research, v.36, n.3, p.18-32, 2005. 
FENSTERSEIFER, J.E. Internacionalização e cooperação: dois imperativos para a empresa do terceiro milênio. 15.ed. READ, n.3, v.6, outubro de 2000.

FENSTERSEIFER, J.E. Internacionalização e cooperação: dois imperativos para a empresa do terceiro milênio. 15.ed. READ, n.3, v.6, outubro de 2000 .

GRANDORI, A.; SODA, G. Inter-firm network: antecedents, mechanisms and forms. Organization Studies, p.183-214, 1995.

IEL; CNA; SEBRAE. Estudo sobre a eficiência econômica e competitividade da cadeia agroindustrial da pecuária de corte no Brasil. Brasília, DF: 2000.

JERONIMO, F.B. A confiança em redes: a experiência de uma rede formada por sete cooperativas do setor agroalimentar no Rio Grande do Sul. 173f. 2005. Dissertação (Mestrado) CEPAN/Universidade Federal do Rio Grande do Sul, Porto Alegre.

MACEDO, L.O.B. Perfil de governança e a coordenação de alianças estratégicas do sistema agroindustrial da carne bovina brasileira. 2009. 203f. Tese (Doutorado) - Escola Superior de Agricultura “Luiz de Queiroz”/Universidade de São Paulo, Piracicaba, 2009.
PERROW, C. Small-firm networks. In: Nohria, Nitin e Eccles, Robert. Networks and organizations: structure, form and action. Boston: Harvard Business School, 1992.

PORTER, M.E. Estratégia competitiva: técnicas para a análise de indústrias e da concorrência. Tradução de Elizabeth Maria de Pinho Braga. 7.ed. Rio de Janeiro: Campus, 1986. 362p.

ROCHA, C. M.; NEVES, M.F.; LOBO, R. Experiências com alianças verticais na coordenação de cadeias produtiva da carne bovina no Brasil. CONGRESSO INTERNACIONAL DE ECONOMIA E GESTÃO DE REDES AGROALIMENTARES, 4., 2003, Ribeirão Preto. Anais eletrônicos... http://www.fearp.usp.br/ egna/resumos/Rocha.pdf.

ROSSETTO, C. R. O estudo das mudanças estratégicas no processo de adaptação organizacional para o gerenciamento do agronegócio. Rio de Janeiro: SOBER, 2000. 7p.

SAAB, M.S.B.L.M; NEVES, M.F.; CLAUDIO, L.G. O desafio da coordenação e seus impactos sobre a competitividade de cadeias e sistemas agroindustriais. Revista Brasileira de Zootecnia, v.38, 2009 (supl. especial) .

YOSHINO, M.Y.; RANGAN, U.S. Alianças estratégicas. São Paulo: Makron Books, 1996. p.3-29. 